\title{
Varicella Pneumonia in Immunocompetent Male: A Case Report
}

Nabeel Badri ${ }^{1}$, Mohamed Teleb ${ }^{1 *}$, Sumayin Ngamdu ${ }^{1}$, Aymen Albaghdadi ${ }^{1}$, Shimma Nagy ${ }^{2}$ and Didia Sclaudia ${ }^{1}$

${ }^{1}$ Department of Internal Medicine, Texas Tech University Health Sciences Center/Paul L. Foster School of Medicine, El Paso, Texas, USA

${ }^{2}$ Department of Pathology Faculty of Medicine, Benha University, Benha, Egypt

*Corresponding author: Mohamed Teleb, Department of Internal Medicine, Texas Tech University Health Sciences Center/Paul L. Foster School of Medicine, El Paso, Texas, USA, Tel: 860-839-3931; E-mail: mohamed.teleb@ttuhsc.edu

Rec date: Jun 20, 2016, Acc date: Apr 07, 2017, Pub date: Apr 17, 2017

Copyright: (C) 2017 Teleb M, et al. This is an open-access article distributed under the terms of the Creative Commons Attribution License, which permits unrestricted use, distribution, and reproduction in any medium, provided the original author and source are credited.

\begin{abstract}
Varicella Pneumonia is a rare condition accounts for high mortality in immune competent and depressed patients. It is estimated to occur 1 in 400 cases of chickenpox infection. Generally, risk factors of Varicella Pneumonia include smoking, pregnancy, and immunosuppression. Signs and symptoms may vary such as tachypnea, cough, dyspnea, fever, and pleuritic chest pain with hemoptysis. Even though these symptoms are nonspecific, they serve as an excellent indicator for pneumonitis. Here is a case report of a Varicella Pneumonia patient, treated successively intravenous acyclovir and resolved without any complication.
\end{abstract}

Keywords: Varicella pneumonia; Herpes zoster infection; Adult

\section{Background}

Onset of Varicella Pneumonia is 1 to 6 days after the appearance of the rash, however still can present earlier [1,2]. Physical exam findings are usually minimal and diagnosis is made by history and chest radiographs [2]. The clinical course can be complicated by severe hypoxemia and respiratory failure $[2,3]$.

The initial treatment is with acyclovir as a standard of care; however the role of corticosteroid remains controversial and often correlates with shorter hospital and intensive care unit stay $[1,4]$

\section{Case Report}

A 64-year-old male without significant past medical history presented with 7 days history of sweating, fatigue, body ache, and continuous fevers. He also had purple-brown rash that was diffused two days later.

Patient admitted a recent contact with another person with chickenpox. His review of system observed to be positive for palpitations, mild dyspnea with exertion, and continuous dry cough. On examination, he had diminished breathing sounds along with mild scattered crackles bilaterally. Finally, the skin exam deemed for vesicular maculopapular lesions on an erythematous base in different stages.

His laboratory findings included White Blood Cell (WBC) count that was unremarkable, however differential showed bandemia of $32 \%$ and thrombocytopenia of $87103 / \mathrm{UI}$. Chemistry analysis was indicative of acute renal failure and his lactate was $284 \mathrm{IU} / \mathrm{L}$, Varicella zoster Virus IgM titer was 3.38 (reference rang is $<0.9$ ).

Chest X-rays showed nonspecific nodular opacities which followed by computed tomography scan (CT) of the Thorax that was remarkable for centrilobular ground glass nodules and tree-in-bud densities with mild mediastinal lymphadenopathy (Figure 1).

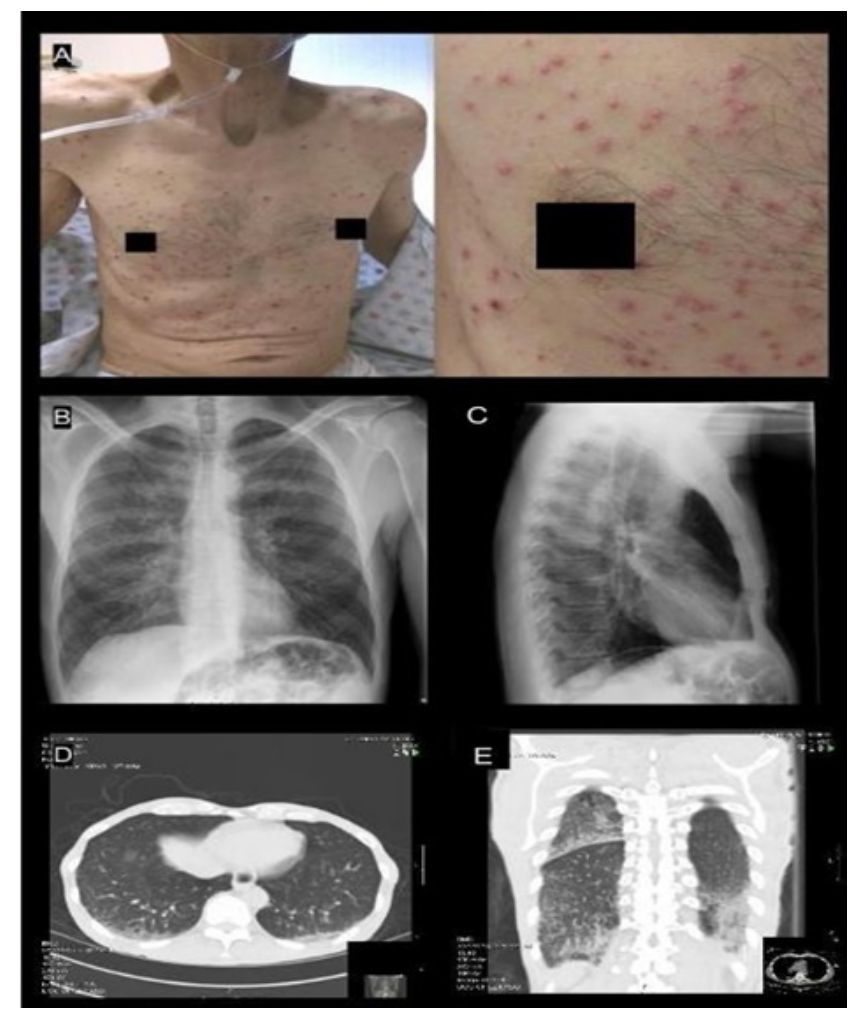

Figure 1: A. Varicella Rash, papules, vesicles, and pustules are concurrently present.

B and C. The chest X-Rays show nodular opacities. D. Thoracic CT scan axial view shows tree in bud. E. Thoracic CT scan Coronal view shows tree in bud and ground glass appearance.

Diagnosis of Varicella pneumonia was made based on the rash, pulmonary symptoms, and the contact with a patient with chickenpox. Additionally, chest X-ray, CT scan findings confirmed the presence of 
Citation: Badri N, Teleb M, Ngamdu S, Albaghdadi A, Nagy S, et al. (2017) Varicella Pneumonia in Immunocompetent Male: A Case Report. Gen Med (Los Angeles) 5: 288. doi: 10.4172/2327-5146.1000288

Page 2 of 2

pneumonia. The patient had then undergone seven days of intravenous acyclovir and his condition resolved without any complication.

\section{Discussion}

Despite the decreased incidence of varicella infection, it still found in large proportion of adults. Varicella pneumonia is usually associated with high morbidity and mortality due to the severity of respiratory symptoms if not treated on time $[1,5]$. The diagnosis is often made by history, physical exam, and high clinical suspicion supported by imaging studies. It was estimated that only $16 \%$ of diagnosed patients have X-rays findings of pneumonia [3]. Given the fact that the disease is highly unpredictable and risk of respiratory failure is high, it is crucial to diagnose it in the early stages and start treatment with acyclovir which is the standard of care. Finally, Primary care providers should actively and routinely screen patients for evidence of varicella immunity (history, serology) and provide vaccination for those without evidence of immunity as primary prevention to decrease the incidence of disease and its complication in this age group [5]. Although, pre exposure vaccination is the optimal salvage strategy, recent evidence suggests post exposure vaccination within 3 days but up to 5 days after exposure is effective in preventing or modifying the severity of Varicella infection, and it is recommended for healthy individuals without evidence of immunity [2,5].

\section{References}

1. Jones AM, Thomas N, Wilkins EG (2001) Outcome of varicella pneumonitis in immunocompetent adults requiring treatment in a high dependency unit. J Infect 43: 135-139.

2. Mohsen AH, McKendrick M (2003) Varicella pneumonia in adults. Eur Respir J 21: 886-891.

3. Hockberger RS, Rothstein RJ (1986) Varicella pneumonia in adults: A spectrum of disease. Ann Emerg Med 15: 931-934.

4. Adhami N, Arabi Y, Raees A, Shimemeri AA, Rahman MU, et al. (2006) Effect of corticosteroids on adult varicella pneumonia: Cohort study and literature review. Respirology 11: 437-41.

5. Marin M, Watson TL, Chaves SS, Civen R, Watson BM, et al. (2008) Varicella among adults: data from an active surveillance project, 1995-2005. J Infect Dis 197: 94-100. 